\title{
El valor de las ideas para el cambio social: Publicidad social, Biopolítica y Neuroética
}

\author{
Isidoro ARroyo Almaraz ${ }^{1}$ \\ iarroy@yahoo.es
}

(Abstracts y palabras clave al final del artículo)

Enviado: 9 de marzo de 2012

Evaluado: 2 de abril de 2012

Aceptado: 25 de abril de 2012

\section{INTRODUCCIÓN}

Actualmente estamos asistiendo a una vertiginosa dinámica de cambios sociales que coincide, como señala Lipovetsky (2011:13), con "la conjunción de fenómenos económicos (liberación de los mercados en un capitalismo planetario), innovaciones tecnológicas (nuevas tecnologías de la información y la comunicación) y cambios radicales de la situación geopolitica". Esta transformación social sin precedentes afecta también a las ONG y muy especialmente a las ONGD con proyectos internacionales que forman parte destacada de la cultura de la globalización, debido a su presencia en todos los conflictos y catástrofes que azotan a la humanidad.

A diferencia del resto de los agentes que participan de la globalización, las ONG promueven una visión alternativa de esa globalización y con ello buscan garantizar la presencia de la sociedad civil en la sociedad global con el fin de impulsar la cooperación internacional para el desarrollo de los más empobrecidos (Del Río, 2011: 40). Sus transacciones son, además de informar y persuadir (Kotler y Roberto, 1992), cambiar dinero por buena conciencia a través de programas y proyectos de desarrollo; crear, distribuir bienes y servicios y fundamentalmente la educación para el desarrollo, es decir sensibilizar, difundir, concienciar, educar, denunciar, (Herranz de la Casa, 2007); es decir, la promoción de sus ideas para el cambio social, que conllevan la difusión de sus creencias sobre la solidaridad internacional que varían, como señala Nos Aldás (2010: 121), ya que unas promocionan ideas y otras se centran en el mercadeo de captación de fondos "objetivos de gestión promocionales $o$ de cambio educativo social, diferencia la publicidad que busca la eficacia relacio-

\footnotetext{
1 Isidoro Arroyo Almaraz (Isidoro.arroyo@urjc.es) es Profesor Titular de Comunicación Audiovisual y Publicidad de la Universidad Rey Juan Carlos de Madrid. Este artículo es parte de una investigación I+D titulada "Desarrollo de un Modelo de Eficacia de la Comunicación Persuasiva del Tercer Sector en las Redes Sociales" (Número: CSO2009-11203. Entidad financiadora: Subdirección General de Proyectos de Investigación. Ministerio de Ciencia e Innovación).
} 
nada con las ventas o captación de fondos, de la publicidad que busca comunicar ideas". Por eso es fácil encontrarse con lemas publicitarios como los recogidos por Balas (2011, 248-249) "Mi cliente me mima", "Tú y tu Fairy contra la lepra", "Tú si que eres grande" que comunican ideas con un claro sentido mercantil.

Más allá de los objetivos de captación de fondos y, muchas veces por encima de ellos, está la sensibilización para el desarrollo lo que conlleva dar a conocer a la propia entidad para sensibilizar a los ciudadanos buscando establecer vínculos racionales y/o emocionales para crear, recordar, modificar o reafirmar conductas dirigidas al cambio social (Balas, 2011: 218-219).

El objeto de estudio de esta investigación es, por tanto, reflexionar sobre qué valor aportan la publicidad social, la biopolítica y la neuroética a las causas sociales. Y parte de las hipótesis de que la lucha por la dignidad humana se manifiesta en el ámbito de la pluralidad de las ideas de las ONG y ONGD a través de la defensa de los derechos humanos y del medio ambiente. Y de que el valor de las causas sociales se incrementa con las aportaciones de las ideas creativas y la estrategia de la publicidad social dirigida al cambio social.

Para ello queremos responder a los siguientes objetivos:

a) Reflexionar sobre el papel de la eficacia de la creatividad para controlar las emociones y los sentimientos que permitan convertir las promesas de las campañas de sensibilización en compromisos ineludibles.

b) Describir los fines de la publicidad social.

c) Describir aquellas estrategias de comunicación social en las que los fenómenos de la creatividad y la planificación favorecen las consecución de objetivos para el cambio social.

d) Reflexionar sobre las nuevas aportaciones de la biopolítica y la neuroética en el procesamiento de las emociones.

Se utiliza una metodología hermeneútica centrada en la discusión, crítica o valoración del papel de la creatividad, la biopolítica, la neuroética y las redes sociales de la web 2.0. Se muestra el impacto de ciertas ideas en el mundo de las ideologías, en la medida en que tal impacto puede distinguirse en situaciones concretas, y puede mostrar los efectos generados.

\section{EL VALOR DE LAS IDEAS DE LAS ONG}

Sus públicos se benefician del valor de las ideas que la mayoría de las veces convierten en su ventaja competitiva, el valor de su poder ideológico en la iconoesfera de las ideas. Sin embargo, el espacio de las ideas depende de instancias de mediación. "Estas instancias pueden adoptar naturalezas y características muy diversas, algunas son constitutivas de ese espacio público, otras se movilizan a través de él, utilizándolo como vehículo. Actualmente, muchos de estos procesos de mediación se constituyen a través de los medios de comunicación de masas (...) Esta mediatización adquiere características particulares y heterogéneas según el tipo de sujetos y dinámicas que movilice" (Saiz, 2008: 1). 
Una de las mediatizaciones posibles está ocupado por un amplio y plural tejido asociativo de entidades del Tercer Sector, entre ellas las ONG, lo que las hace muy vulnerables y dependientes de la comunicación y las experiencias sociales.

Por ejemplo, en Nueva Zelanda existen 97.000 ONG lo que representa el 5\% de la economía del país, comparable a la industria de la construcción (Zorn, Flanagin y Shoham, 2011:2). En España son más de 300.000 asociaciones las registradas en el Ministerio del Interior, de ellas en el apartado 73 de acción social en las categorías 7314 y 7315 , las denominadas humanitarias con proyección en el extranjero ${ }^{2}$, son unas 9000 que gestionan la mayoría de los servicios de la economía social y gestionan una buena parte del 20\% del gasto público (Martín, 2010: 164).

Todas estas ONG no son iguales, varían según sean sus visiones del mundo, las podemos diferenciar fijándonos en cuándo aparecieron, quiénes les brinda su apoyo o qué grado de confianza generan. En el primer caso, según Korten (citado en Arroyo y Martín, 2011: 249), podemos hablar de ONG asistencialistas, autosuficientes, de cambio estructural o de transformación. En el segundo, según Gómez Gil (2004:4), de subsidiarias, que obtienen el apoyo del estado; instrumentales, creadas por empresas multinacionales para defender sus intereses; oportunistas, especializadas en captar recursos y alter-mundialistas, surgidas ante el avance del proceso de globalización neoliberal. O en el tercero, según Fowler (citado en Bala 2011:179180), podemos hablar de ONG de maletín, comerciales, delictivas, de donantes, de pega, gubernamentales, creadas y mantenidas por el gobierno, mi propia ONG, fantasmas o de políticos.

Las ideologías son también un elemento diferenciador de las ONG a partir de las cuáles nos ofrecen sistemas de creencias, estables y permanentes apoyados en ritos y liturgias con las que conjuran los grandes miedos que azotan a la humanidad, que no son otros que aquellos que se reflejan en las grandes causas sociales que defienden y que, según Alvarado (2003), son los males referidos a la salud y el bienestar público y social, la protección del entorno natural y urbano, la solidaridad internacional y la marginación y, con ella, todas las formas de discriminación.

Sin embargo, las ideologías de las ONG que a veces las diferencia, también las unen, la mayoría de ellas comparten el denominador común de la cultura moderna, el pluralismo: es decir la capacidad de integrar distintas ideologías e incluso distintas religiones en los modernos estilos de vida multiculturales.

Lipovetsky (2011: 19) habla de cultura mundo cuando se refiere a esa cultura moderna y que consagra, a su modo de ver, las dos grandes ideologías del siglo XXI: la ecología y los derechos humanos. A su vez, ambas dos son dependientes de otras. El ecologismo también es parte del discurso de empresas que contaminan y las discusiones más serias sobre los derechos humanos arrancan en el siglo XVIII, anteriores incluso a la revolución francesa. Ambas entran en contradicción con los valores dominantes liberales, es decir el dominio del mundo occidental y la economía de mercado basada en el crecimiento y el progreso. Esto hace que se generen nuevos

${ }^{2}$ La financiación de los proyectos AECID de 2012 por sectores y organizaciones con mayor financiación se pueden consultar en: http://www.aecid.es/galerias/ongds/descargas/INFORME_ONGD 2012.pdf 
conflictos; de una parte el conflicto político entre la denominada alianza de civilizaciones frente al choque de civilizaciones y de los conflictos étnicos e identitarios que conlleva una crítica a la hegemonía occidental y su reivindicación del fin de la historia (Fukujama, 1992) y, de otra parte, los conflictos derivados del calentamiento global.

Las ONG asumen la ideología global de la defensa de los derechos humanos y especialmente las ONGD a través de su omnipresencia en los conflictos y de su gran capacidad de adaptación para resolver los problemas sociales. Son los primeros agentes altruistas en aparecer allí donde se produce un conflicto poniéndose siempre de parte de la defensa de los derechos universales. Una vez más "La ideología universalista de los derechos humanos como valor central se expresa en el poder de los movimientos humanitarios y de las ONG transnacionales cuyas intervenciones y cuya capacidad de actuación no cesan de aumentar" (Lipovetsky, 2011: 20).

Pero también lo hacen desde la intervención social, "las ONG despuntan también en la era de la globalización como uno de los agentes destacados que emergen ante la debilidad de los estados-nación y la aparición de nuevas dimensiones de intervención social como consecuencia de la necesidad de reparar en la sociedad los daños causados por una economía de mercado sin reglas, como la que se asiente en la actualidad" (Gómez Gil, 2004: 2).

Las ONG asumen también la ideología de la defensa del medio ambiente y cuestionan el modelo ambicioso de la civilización occidental que nos ha llevado a la crisis del medio ambiente y al calentamiento global del planeta. Se instalan en un punto de vista que cuestiona la imposibilidad de generalización del modo de vida occidental basado en el consumo descontrolado y en el abuso y la expoliación de los recursos naturales y reivindica un modelo de economía sostenible y de economía social. Esta idea de un mundo infinito en expansión de progreso indefinido que surge con la filosofía idealista y se instala en el pensamiento positivista desde la ilustración, ha sido durante siglos el leit motiv que ha regido los designios de la revolución industrial; pero que ha encontrado su freno en las alarmas generalizadas sobre los efectos del calentamiento global y que busca con el concepto de economía sostenible que cualquier crecimiento económico no se fundamente en la destrucción de la vida en el planeta.

La defensa de los derechos humanos y la ecología entran en contradicción con las teorías del fin de las ideologías con el que se había interpretado la historia. Sin embargo, el fin de las ideologías es en sí mismo una ideología. Sabemos que la ideología ganadora siempre se ha defendido así mismo como no ideología. Luego podemos decir que la ideología del fin de las ideologías no es más que la representación de la ideología que ha salido victoriosa de la contienda de la guerra fría y cuyo triunfo busca perpetuarse como la ideología que supera a las ideologías (Serrano, 2011).

\section{UN NUEVO SISTEMA DE CREENCIAS, LA VOLUNTAD DE PODER}

Estamos pues ante una nueva ideología dominante, un nuevo sistema de creencias que impone un afecto por encima de otros: la ideología que impone la voluntad 
de poder, tal y como la definió Friedrich Nietzsche y la difundió Martín Heidegger, distinta de la voluntad de poder político, del dominio político que intenta definir el sentimiento básico que domina la visión del mundo. Sin embargo, lo contrario, que no tengamos ninguna voluntad de poder, es proponer que otro asuma el $100 \%$ de poder sobre nosotros. Es decir, que seamos esclavos. Por tanto, tal y como lo señaló Berlin (1958) se pueden identificar dos conceptos diferentes de libertad. La primera, la libertad negativa que concierne únicamente a la libertad de oportunidades y donde la voluntad de poder se somete a sus posibilidades y, la segunda, la libertad positiva en la que elegimos porque somos dueños de nuestra propia vida: "Negative freedom is, roughly, a matter of which doors lie open to you, it is concerned exclusively with opportunities; positive freedom is a question of whether or not you can go through the doors, whether you are master of your life". ${ }^{3}$

La ideología autoafirma al hombre a través de sus valores, como dice Kaplún (1998: 140) "el poder de la ideología consiste en que opera «desde dentro» del sujeto: el dominado la internaliza e inconscientemente la incorpora" y en las sociedades de consumo se ha trasladado a una autosatisfacción de los propios deseos que configuran una cultura de insatisfacción y de agresividad y que "hace triunfar la publicidad, que nos hace soñar con la mejora permanente, que nos lleva a los centros comerciales, que obliga a las empresas a seguir reinvirtiendo para crecer, y a los sistemas económicos de los países a medir la salud o la falta de salud de sus economías en términos de crecimiento, de manera que el bien está del lado del crecimiento y la recesión o simplemente el estancamiento son signo de enfermedad o de debilidad, dos de los términos que Nietzsche usaba cuando quería condenar aquello que se alejaba de la voluntad de poder" (Serrano, 2011: 39).

Estamos, en definitiva, ante un modelo ideológico triunfante que no tiene que competir con otras ideologías basadas en el poder omnímodo de la razón y por tanto excluyentes y portadoras de la verdad absoluta, como ocurrió durante la guerra fría entre los dos grandes bloques.

Esta nueva ideología triunfante que reivindica un mundo mejor a través del crecimiento constante y sostenible relacionado con el progreso, se las tiene que ver con sus propias contradicciones, las que el afecto dominante de voluntad de poder crea. Lo vemos cada día representado en la amenaza constante de los mercados hacia los gobiernos y de éstos hacia los ciudadanos.

Esta nueva ideología no puede ahogarnos, sino que debe organizar y jerarquizar los afectos y favorecer las aspiraciones de justicia, de ética y de pluralismo, de lo contrario ocurrirá lo que pasó con el derrumbe del mundo soviético donde la voluntad de poder de satisfacción de los deseos estaba solo en los dirigentes y no en la población reeducada bajo los afectos del miedo. Los afectos no se pueden modificar por la fuerza o mediante la represión, porque provocan la aparición de un afecto dominante, el miedo que dominará el resto de la vida de las personas (Serrano, 2011: 166). En palabras de José Antonio Marina (2010) debe favorecer la inteligencia

\footnotetext{
3 Isaiah Berlin (1958), p. 1. en línea http://www1.nsd131.org/classpages/bwilliamson/Shared\%20Documents/Two\%20Concepts\%20of\%20Liber ty\%20Berlin.pdf consultado el 07/03/12.
} 
social, se trata de favorecer la pluralidad de las ideas para desarrollar una inteligencia colectiva, o mejor dicho una inteligencia compartida.

Por tanto, frente a la sociedad inteligente basada en indicadores de economía de mercado, tales como el PIB, la tasa de natalidad, las estadísticas sobre delitos, etc. debemos contraponer una sociedad plural que incorpore también los índices de felicidad social o los indicadores de economía social. En definitiva, frente a la economía de los mercados debemos reivindicar lo que Graham (2001) definió como economía de la felicidad; el bienestar de un país, la sanidad de su pueblo, la educación de los niños y de los jóvenes, etc.

De lo contrario pasaremos a una sociedad fracasada donde la voluntad de poder que gobierna nuestros afectos, en lugar de ampliar las posibilidades de acción de los ciudadanos (empowerment), creará más problemas que soluciones.

El problema reside en cómo definir la felicidad y sus indicadores. Muchos autores (Easterlin, 1995; Stevenson y Wolfers, 2008; Tella y MacCulloch, 2008) vinculan las condiciones económicas a la felicidad, pero tal y como señala Corral (2011: 2) "existe un desacuerdo sobre el punto hasta el cual son los factores económicos a nivel nacional o a nivel individual los que importan".

La filosofía clásica aporta la convicción de que la felicidad se obtiene asumiendo límites a nivel individual; los que establece la naturaleza con sus carencias, los procedentes de las divinidades y las religiones con sus códigos de virtudes y vicios; los que se derivan de las ideologías con sus modelos de hombres perfectos y ahora con la postmodernidad, los que provienen de la estimulación permanente y que incentivan la omnipotencia y la realización máxima de la voluntad de poder del hombre moderno. Pero cómo conjugar vivir sin límites con ser felices o como dice Serrano (2011:76): "cómo es posible entender la felicidad alli donde no hay límite que la regule, donde falta la pieza básica a partir de la cual gestionar el deseo, junto con el temor, el dolor y las demás limitaciones básicas de los humanos, y cuyo resultado es el ideal de una vida feliz" El propio autor nos da la solución "hoy por hoy ese límite descansa en la idea de los derechos humanos” (op. cit: 117) .

Las ONG participan por tanto de esta ideología común de búsqueda de la felicidad a través de la lucha por la dignidad humana que se manifiesta en el ámbito de su propia pluralidad de ideas y defensa de causas sociales para las que utiliza herramientas tan poderosas como la publicidad social, una publicidad en su tercer tiempo en palabras de De Andrés (2010: 71 y ss.) que aunque "probablemente nunca es la solución (definitiva, inmediata) de nada, pero sí puede ser una vía de resoluciones, mediatas, temporales, revisables. Propicia cambios de actitudes, y su creatividad hace visible lo invisible, inteligible lo ininteligible", una nueva publicidad entre lo comercial y lo social, entre objetivos y fines a favor de las personas, de las utopías, de la difusión optimista de las ideas, dando la palabra a los colectivos sin voz y generando un diálogo intercultural, pero también aportando sus propias contradicciones lo que, en palabras de Latorre (2001: 106) consisten en limitar la voluntad de poder de los públicos; favorecer un consumo responsable, denunciar cuando se especula con los alimentos o hacer cosas poco atractivas, como donar sangre, pagar impuestos, donar dinero. Esta contradicción plantea el problema, nada menor, de responder a 
cómo transformar la necesidad de bienestar de la sociedad en una necesidad individual a satisfacer o cómo convertir las promesas en compromisos ineludibles.

\section{LA PUBLICIDAD SOCIAL, UNA TERCERA VÍA}

La publicidad social ayuda a resolver esa contradicción en la medida en que selecciona los valores más destacados de la realidad que transporta a través de metáforas.

La verdad metafórica que ofrece la publicidad realza las promesas que crean compromisos y obligaciones en quiénes las proponen, porque les obliga a cumplirlas, pero también en quiénes se las creen, porque las convierten en las razones con las que construyen el sentido de sus vidas.

La publicidad social es, por tanto, una enorme promesa que ofrece argumentos racionales y/o emocionales para que los públicos encuentren razones para tomar decisiones y adquirir compromisos, por ejemplo, "si bebes no conduzcas", "póntelo, pónselo". Cada uno se compromete con su verdad, entre otras razones porque la ha construido dentro de sí a través del lenguaje humano. Todos los lenguajes humanos efectivos, y la publicidad es uno de ellos, son actos de habla que tienen algo de promesa que sirven para crear razones para la acción, independientemente del deseo (Searle, 2000:193).

A la vez que la toma de decisiones entraña juicios morales porque sirven para discriminar lo bueno de lo malo, los dilemas morales personales con los que los públicos se enfrentan a las metáforas de la publicidad social implican la activación de áreas cerebrales asociadas con la emoción y con la cognición.

Sabemos, siguiendo los argumentos de Damasio (2005), que estas decisiones se toman más desde la emoción que desde la razón. Muy especialmente cuando hay cercanía física. Cortina (2011:70 y ss.) considera que "cuando hay cercanía física se activan los códigos morales de supervivencia profundos, mientras que cuando no la hay, se activan otros códigos cognitivos más fríos (...) Por eso afecta emocionalmente la situación de la gente necesitada y cercana, cosa que no ocurre con las gentes necesitadas que no conocemos"

Sabemos que quién controla la imaginación controla las emociones en la medida en que éstas se construyen con relatos y se expresan con palabras, imágenes, sonidos y músicas.

En definitiva, el control de la imaginación supone el control de la emoción y dado que la creatividad influye en la imaginación, se deduce que el poder de la creatividad conlleva el control de las emociones y con ellas de los sentimientos.

Los dos sentimientos más vivos que estimulan la voluntad de poder son el amor y el odio.

La publicidad comercial mayoritaria que fomenta la tendencia al exceso utiliza el odio, y lo hace desvirtuando las virtudes desde la parodia y convirtiendo a su vez el odio en virtud en la medida en que estimula el deseo de consumir o de obrar, base de la voluntad de poder.

Algunas investigaciones (Arroyo, 2006; Arroyo y Mamic, 2009) muestran que la tendencia mayoritaria de la publicidad comercial analizada fomenta la soberbia, 
la codicia y la lujuria, destinadas al exceso de consumo; donde el discurso publicitario muestra personajes cargados de presunción e indiferencia, con una voracidad acaparadora de cuanto producto alcancen sus ojos.

El odio convierte el deseo en obligación. Esto es porque el odio es más poderoso que el amor, y las representaciones de éste tales como la lealtad y el compromiso hoy se entienden como frenos a la voluntad de poder "el amor ha dejado de ser representado como la aspiración a la unidad o a la naturaleza, es decir, como la máxima expresión del reconocimiento del límite" (Serrano, 2011: 199).

A cambio el odio dice más sobre nosotros mismos y contribuye a moldearnos y acercarnos al modelo de la nueva ideología dominante, la de la voluntad de poder, "la gran verdad se cifra en que el mal en el mundo es más importante que el bien. El bien es la base, pero la cumbre es el mal" (Bataille citado en Marina 2011: 83).

Pero justo aquí es donde adquiere mayor importancia el discurso de las ONG. Sin embargo como señala De Andrés (2010:68 y ss.) la publicidad social no se distingue de la comercial por sus objetivos, actores o medios y mensajes, sino por sus fines "La finalidad es lo decisivo en un mundo de valores, de derechos, de ciudadanos. La finalidad publicitaria estaría siempre en las personas, en la comunicación responsable entre personas e instituciones, en la cohesión cultural".

Esta es la labor que deben hacer estas organizaciones con la comunicación, transformar los valores tradicionales a través de la eficacia de la creatividad (Arroyo, Baños y Rodríguez, 2009; Baños y Rodríguez, 2009), de la biopolítica (Foucault, 2009, Agamben, 1998, Esposito, 2004, Serrano, 2011) y de la neuroética (Cortina, 2011) para dotarlos de nuevas representaciones. Cambiar la fuerza del odio estructural en ideales de defensa de los derechos humanos y protección del medio ambiente "Ese odio básico transfigurado que como tal puede asumir incluso la forma de la solidaridad". Ese odio que impida callarse ante la presencia de situaciones infames y que fuerce a la indignación (Boltanski, L. Y Chiapello, E., 2002: 48).

Es lo que Marina (2011:73 y ss.) define como las contradicciones de los vicios capitales "Una pasión puede convertirse en virtud o en vicio, dependiendo de si se integra en la anábasis o en la katábasis" (2011: 84) 4 ya señalados por Himmelfarb (1995).

Así, recupera las viejas pasiones consideradas vicios como un motor para emprender las tareas más comprometidas y difíciles; utilizar la soberbia para buscar la excelencia, la megalopsijía 5 ; la ira para indignarse frente a los excesos de la globalización, conseguir un bien o evitar un mal. La envidia en admiración que estimula el deseo de participar en acciones de ayuda porque las ve hacer a otros y puede convertirse en un motor de progreso. La avaricia en generosidad que estimula las donaciones y el voluntariado. La lujuria, una vieja transversal de la publicidad a la que erotiza, se transforma simbólicamente en la ternura que nos satisface con el cuidado de los más débiles. La gula que acapara, deja paso a un mejor reparto de alimentos en el planeta que, a modo de vasos comunicantes, transfiera alimentos desde los obe-

\footnotetext{
4 Entendida la anábasis como afán de superación .

5 El emprendimiento voluntario de cosas altas.
} 
sos a los famélicos; desde el primer mundo, transido de problemas de bulimia y anorexia, hacia el tercer y cuarto mundos hundidos en la hambrunas endémicas. La pereza en actividad solidaria capaz de sacarnos del aburrimiento y de llenarnos de libertad para actuar, autonomía para elegir y dignidad para ser felices.

\section{EL VALOR DE LA CREATIVIDAD EN LA PROMOCIÓN DE LAS IDEAS}

La comunicación para promover el desarrollo es un objetivo cada vez más importante para las Organizaciones sin ánimo de lucro (Servaes citado en Rau de Almeida, 2006) sin embargo existen aún dificultades para definir su forma de trabajo. La comunicación de las ONG ha pasado de la improvisación y la falta de previsión a la profesionalización pasando por una etapa de comunicación mercadeada (Erro, 2003:17-30).

La creatividad incrementa el valor de la comunicación de las causas sociales porque se apoya en el valor de sus ideas que facilitan la transformación de la representación de la realidad, tal cual es, en la ficción, tal como debería ser, como consecuencia de la acción colectiva solidaria.

La idea del compromiso moviliza grandes cantidades de personas con modelos de contratos que se recogen en la enorme oferta de propuestas que sugiere el campo semántico de la solidaridad, con acciones como: participar, apadrinar, adherirse, unirse, ayudar, proteger, ofrecer, defender, fraternizar, donar, amar,... así, por ejemplo, el contrato apadrinar se aplica indistintamente a: un niño, un proyecto, un gato, un cura, un árbol, etc.; el contrato donar a: sangre, semen, óvulos, órganos, células del cordón umbilical, el cuerpo para la ciencia, medicinas, etc.; el contrato defender a: los derechos humanos, la salud, la alegría, los derechos del niño, los pobres, etc.; el contrato proteger a: los inocentes, los usuarios, nuestros hijos en facebook, etc. Con la crisis las campañas publicitarias dirigidas a la captación de colaboradores, socios o voluntarios no han conseguido aumentar su número, pero están sirviendo para detener las bajas 6 .

Moviliza grandes cantidades de recursos económicos. Lo hemos visto con la campaña Pastillas contra el dolor ajeno ${ }^{7}$ de Médicos sin Fronteras lanzada en noviembre de 2010 y que según Ana Pineda, Directora de Captación de Fondos, ha permitido en tres meses captar tres millones de euros y que actualmente van por más de tres millones y medio.

Utiliza personajes famosos para apoyar las causas sociales, como fue el caso de Amaia Montero que puso la voz del nuevo christma musical de Unicef8; otras veces otras marcas comerciales, como fueron los casos de:

\footnotetext{
${ }^{6}$ Datos de la Consultora Estratégica Bain recogidos en el reportaje titulado "Las ONG buscan socios fieles" de Carmen Sánchez-Silva publicado en El País de 16/10/2011.

${ }^{7}$ La presentación de la campaña se puede ver en: http://youtu.be/SCVOPioT4Vs

${ }^{8} \mathrm{La}$ audición se puede escuchar en: $\underline{\mathrm{http}: / / \text { youtu.be/sLKqhCugExM }}$
} 
- La Fundación FC. Barcelona y Unicef que pusieron en marcha, con motivo del día mundial contra el sida, la iniciativa solidaria de sensibilizar sobre el sida infantil en países en vías de desarrollo9.

- Pikolín que presentó un decálogo contra los daños al descanso con dos documentales de víctimas del ruido de Sevilla y Barcelona ${ }^{10}$.

- Alain Afflelou que diseñó una estrategia social para vender más gafas basada en adelantar las gafas a los parados por un tercio de su valor con la esperanza de recuperar su valor al final de la crisis económica11.

Obtiene notoriedad con niveles de excelencia creativa que se premia en los festivales de publicidad que contemplan esta categoría con diferentes denominaciones: campañas de servicios y campañas de bien público (FIAP), campañas de servicios públicos sin ánimo de lucro (El Sol); campañas sociales de divulgación y de administraciones públicas o campañas de responsabilidad (CdC). También existen los Premios Sombra (Consume hasta morir) como un contra-certamen alternativo al Festival El Sol para premiar las peores campañas sexistas, xenófobas o insolidarias. El Green Effie Award para premiar a las mejores campañas verdes, etc.

Las agencias de publicidad dedican un departamento en exclusiva a esta labor, como es el caso de la agencia Contrapunto con su departamento de Contrapunto Social. Otras agencias publicitarias, que generalmente son las empresas publicitarias más importantes del sector, prestan sus servicios de creatividad de forma desinteresada y se encargan de la realización de las campañas publicitarias de las ONG. así, por ejemplo JWT Delvico colabora con El Casal dels Infants en Barcelona a través del proyecto "mi primer libro", en apoyo a proyectos de alfabetización e integración social en más de 20 países. La Despensa trata de salvar una lengua en Camerún que solo hablan 8 personas en el mundo, etc.

Utiliza los múltiples formatos de comunicación que aporta la web 2.0 a través de las redes sociales. Las ONG blogean, twitean, ..., tienen perfiles en las grandes redes Facebook, Tuenti, YouTube, Twitter, etc., en mundos virtuales como Second Life (Baños y González, 2011) porque les permiten entablar diálogos con sus públicos, tal y como señala Beltrán (2007: 32): "Idealmente todas las comunicaciones debieran ser horizontales".

Aunque las ONG utilizan fundamentalmente sus páginas web para darse a conocer y para difundir sus proyectos y no aprovechan todos los beneficios de la interactividad (Marí, 2007: 459-460), hemos observado que cada vez son más las organizaciones que utilizan estrategias en la web 2.0 (Arroyo, Baños y Rodríguez, 2012: 6 y 7; Méndiz, Victoria, Arroyo, 2013) porque éstas están tomando conciencia de que los proyectos de desarrollo implican la participación de los públicos en las movilizaciones masivas y éstas no pueden ocurrir si no hay comunicación (Beltrán, 2008: 36). Utilizan, entre otras:

\footnotetext{
${ }^{9} \mathrm{El}$ spot de la campaña se puede visualizar en http://www.youtube.com/watch? $\mathrm{v}=\mathrm{x} 55293 \mathrm{~K} 7 \mathrm{Bws}$

10 Presentación de la campaña en: http://www.youtube.com/watch?v=pn-YUyb4vno

11 Campaña de Alain Affleou, de la mano con los parados

http://www.youtube.com/watch?v=zVetpqsfz9Q
} 
- Estrategias dirigidas para llamar la atención utilizando perfiles con titulares impactantes: así, por ejemplo, Acción contra el Hambre, creó la página Señoras que ven morir a sus hijos porque no tienen agua potable y consiguió 6.283 fans en los primeros 20 días, cantidad que llegó a 9.025 personas. Otras, como Cambio tesoros del Vaticano por comida para Africa, ite apuntas? ya llevan 2.674.352 personas. Más de un millón de usuarios han firmado la petición lanzada por la Organización de las Naciones Unidas para la Agricultura y la Alimentación (FAO); cuando comenzó la campaña en la web www.1billionhungy.org. Médicos sin Fronteras no llegaba a los 5.000 fans, ahora está en 174.593. Amnistía Internacional España empezó con 3.167 y ahora tiene 111.578.12

- Estrategias de uso de mensajes concretos orientados a la acción Así, por ejemplo, No solamente digas, firma esta petición y nosotros enviaremos cartas impresas a estas persona en el congreso, etc. ${ }^{13}$ La Fundación Khanimambo ha lanzado una aplicación en Facebook que circula por redes sociales que no pide ayuda, sino que ayuda a todas aquellas personas en España que necesitan sonreír. Son los niños de Praia Xai-xai en Mozambique quienes hacen donativos a las personas españolas. Son donativos de felicidad para resolver problemas del primer mundo como que no te abrochen los pantalones del verano pasado o que te pases el día entero trabajando en la oficina. ${ }^{14}$

- Estrategias de ciberactivismo y cibervoluntariado, por ejemplo, la campaña Barbie cortamos, no salgo con chicas que desforestan. Ken..$^{15}$ La comunidad de Greenpeace España que creó una intranet exclusiva para sus más de 103.000 socios.

- Estrategias de viralidad, creando flashmob. El vídeo Frozen Grand Central donde 200 personas se quedan congeladas en la Gran Central de Nueva York ha sido visto por 28.489.458 de personas en YouTube (Caravantes, 2011: 163).

- Estrategias centradas en dar la palabra a las víctimas de las causas sociales. La experiencia del crowdsourcing, que consiste en que una multitud de destinatarios comparte en tiempo real sus opiniones sobre un mismo tema de su interés. Como ocurrió con el Proyecto Katine (subcomarca de Uganda) financiado por el Barclays y difundido a través de los lectores que también aportaban donaciones (Ford, 2011: 167-176). The Guardian se unió con dos ONG African Medical and Research Foundation (AMREF) y Farm Africa (FARM) en un proyecto de desarrollo en la región de Katine en Uganda para que los residentes publicaran fotos y vídeos en The Guardian. Se activaron chats y blogs en directo para que las personas de todo el mundo pudieran comunicarse con los habitantes de la Región Ugandesa. A la vez que los redactores del periódico escribieron artículos

12 Todos los datos de las ONG han sido consultados el 14/04/2012 en Facebook.

13 http://yankana.org/index.php/2009/02/utilizando-facebook/

14 Noticia publicada en la p.24 de la revista El publicista n $^{\circ} 253$ del 1-15/11/ 2011.

15 Noticia publicada en la página web http://www.greenpeace.org/argentina/es/noticias/Barbie-Lamuneca-mas-famosa-involucrada-en-la-destruccion-de-selvas-de-Indonesia/. Esta campaña se puede ver en http://youtu.be/FzEO 7eEbNo 
periodísticos, AMREF Y FARM publicaban sus informes en la primera página de The Guardian.

Utilizando una estrategia similar consistente en dar la palabra a las víctimas de las causas sociales, la agencia Altrafoma ha desarrollado la campaña de sensibilización La universidad de la calle para la ONG Arrels Fundació, que atiende a personas sin techo, basada en redes sociales ${ }^{16}$. Se creó el perfil de Twiter@placido_mo a través del cual tres personas sin techo atendidas por la fundación relataban su experiencia real, narrada en presente, recordando el pasado que vivieron a miles de personas. El perfil sigue vivo como plataforma de diálogo y debate.

\section{LAS IDEAS EN EL ÁMBITO DE LA BIOPOLÍTICA}

Tomamos aquí el concepto de biopolítica de acuerdo con Foucault (2009) y descrito por Serrano (2011: 127) que la define como un poder sobre la naturaleza que queda limitado solo por la jurisprudencia y muy particularmente por los mercados.

La biopolítica en este sentido es la preocupación del Estado por los nuevos hábitos de comportamiento de la población, desatendiendo, según algunos autores (Alvarado y De Andrés, 2005; Gómez, 2005), parte de sus antiguas responsabilidades de prestación de servicios que depositan en las ONG y desplazando sus preocupaciones hacia los nuevos espacios de control biológico que, como señala Serrano (2011: 145), van "desde la regulación de la venta de tabaco, incluyendo el uso de todo tipos de drogas, pasando por otras infinitas normas que tienen que ver con la higiene, la salud, los hábitos alimenticios, etc." Y que forman parte de la vida cotidiana y conforman los actuales modelos de virtudes públicas que configuran la cultura light de culto a las dietas, al gimnasio y a las causas ecológicas, con los denominados light green y greenies, sujetos preocupados por llevar un estilo de vida dentro de los cánones ortodoxos de la ecología.

Existe, por tanto, una publicidad institucional que convierte al Estado en un anunciante importante de este país, ideólogo que legitima un nuevo orden social preocupado más por la gestión de los afectos de los ciudadanos, que por su bienestar social y que fundamenta su acción de comunicación en recoger, dirigir y expresar sus deseos en múltiples campañas que den satisfacción a su voluntad de omnipotencia. Incluso en momentos de crisis como el actual en España, la prioridad del plan de medios de la Administración General del Estado es promocionar durante 2013 los hábitos saludables y de seguridad de la ciudadanía, el apoyo a las nuevas tecnologías y el conocimiento de la información sobre derechos y obligaciones legales de los ciudadanos respecto a las instituciones públicas.

Los recortes vuelven a predominar un año más en la Administración, y se reducirá la inversión publicitaria en 2013 en un 6,5\% respecto a 2012. Con este nuevo ajuste se habrá reducido la inversión en publicidad institucional en un $87,7 \%$ respecto al presupuesto del año 2007, anterior a la crisis. Y, a pesar de ello, se llevarán a

\footnotetext{
16 Noticia publicada en la p. 22 de la revista El publicista n ${ }^{\circ} 253$ del 1-15/11/2011.
} 
cabo 44 campañas de publicidad institucional focalizándose en 3 grandes campañas con gastos superiores a 3 millones de euros sobre seguridad vial de la Dirección General de Tráfico, Red.es y la proximidad de las Fuerzas Armadas, reconocimiento y captación del Ministerio de Defensa ${ }^{17}$.

Pero no sólo el Estado o los colectivos comprometidos intervienen en los temas sociales, cuando se trata, por ejemplo, de la conservación del medio ambiente, también los mercados lo hacen y para ello utilizan a los mass media creando una auténtica sensibilidad verde que recorre el planeta. Esto se traduce en una presencia masiva de campañas publicitarias centradas en la ecología y la economía sostenible. A este fenómeno se le ha bautizado con el anglicismo de greenvertising que engloba a los anunciantes, sus marcas y a los propios consumidores. Los anunciantes están muy involucrados en la causa ecológica, pero como señala Pacheco (2010: 113): "cuando comenzamos a profundizar e indagamos surgen dudas razonables acerca de la veracidad del discurso verde". Por eso frente a la marea verde del greenvertising ha surgido la marea blanca del greenwashing y el culture jamming. La primera, para denunciar la publicidad engañosa de aquellos anunciantes mentirosos que pregonan un comportamiento respetuoso con el medio ambiente pero que sus productos no lo son. La segunda, para instalarse en los medios de comunicación produciendo mensajes críticos utilizando el mismo lenguaje publicitario, creando con ello mensajes subversivos. Son los denominados mensajes contra-publicitarios (Pacheco, 2010: 118-143).

\section{LAS IDEAS EN EL ÁMBITO DE LA NEUROÉTICA}

Las modernas técnicas de neuroimagen constituyen hoy en día una nueva realidad. "Si el saber se equipara al poder no es tanto porque la técnica sea ideología o instrumento de dominación. Su significado es más radical: la técnica, la poiesis, es la realidad"' (Serrano, 2011: 129). La nueva realidad se denomina imágenes cerebrales, que desempeñan un papel clave en el procesamiento de las emociones. Hay una nueva realidad que va desde el lóbulo frontal hasta el sistema límbico que explica cómo controlar las emociones y con ellas los juicios morales que tanta influencia ejercen sobre nuestras cogniciones y nuestros pensamientos solidarios.

Cortina (2011:65 y ss.) relaciona la cognición y la emoción con los juicios morales a través de áreas cerebrales asociadas y determina que el cerebro toma decisiones influido por las zonas asociadas con la emoción y la cognición moral que hace que nos afecte emocionalmente la situación de la gente necesitada y cercana y que esto no ocurra con las gentes que no conocemos. Habla del imperativo neuroético que establece que "Amarás al cercano y rechazarás al lejano" y que lo ejemplifica con los dilemas morales de Unger (1996), en el que se solicita una donación de seis-

17 Todos estos datos han sido tomados del Plan de Publicidad y Comunicación Institucional 2013, que puede consultarse en "El anunciante publico agoniza". Informe Publicidad institucional (1-15 marzo, 2013). El Publicista, 280, pp.22-24. 
cientos euros para salvar a un niño que vive en un país muy lejano y que morirá si no se le ayuda. Surge la paradoja de que teniendo moralmente que ayudar, el cerebro, tal vez relajado por la distancia del conflicto, encuentra argumentos para no colaborar, tales como: el dinero nunca llega a los desfavorecidos, se lo apropian los gobernantes o las propias organizaciones, etc., sin embargo si lo que se le solicita es atender a un hombre herido cubierto de sangre y que se desangrará si no le lleva a un hospital, pero que se salvará si le recoge y le traslada en su coche nuevo, la mayoría de la gente encuentra razonable atenderle, aunque en el traslado le manche la tapicería del coche y ésta le cueste seiscientos euros.

Si el imperativo neuroético nos obliga a odiar estamos condenando el discurso de los derechos humanos y la solidaridad. Surge por tanto la denominada paradoja del altruismo que, aún estando motivados emocionalmente para amar al cercano, somos capaces de preocuparnos desinteresadamente por los lejanos. Martín Requero (2010: 19) define la conducta altruista "como la que realiza una persona, que haciendo uso de su libertad y ajena, por tanto, a todo tipo de presión, decide ofrecer sus servicios con el fin concreto de ayudar a los demás de forma desinteresada". Luego, las conductas altruistas no se explican, como señala Cortina (2011: 121) " con la ficción del hombre económico que trata de maximizar sus ganancias a toda costa; pero tampoco se explican (...) con el altruismo genético que se expresa en la Regla de Hamilton: "obra con los demás según la medida en que compartan tus genes"; es preciso contar con la realidad de un hombre capaz de reciprocar. Para ello es necesario cultivar y educar las emociones. Son muchos los ejemplos en los que las ONG han asumido este compromiso, el proyecto más consolidado (Pacheco, 2010: 122) es Consume Hasta Morir desarrollado por Ecologistas en Acción que tratan de promover un comportamiento crítico hacia el consumo y los medios de comunicación. Pero son muchos más los que están entendiendo como dice Cortina (2011: 123) que "el idioma moral de las diferentes culturas, es mucho más acertado que intentar descubrir principios con contenido"

Los principios que cada día se ponen y se quitan parecen levantar una montaña y luego desaparecen sin dejar rastro. Solo desde el entendimiento y el respeto a lo principios éticos que nos exigen límites para ser felices, podremos combinar los dos principios fundamentales de la globalización, pluralidad y universalidad. No podemos inventar para cada problema esos límites, se necesitan axiomas vitales entendiendo que la ética es reflexiva y requiere un debate permanente.

\section{CONCLUSIONES}

Como corolario de la interpretación hermenéutica realizada, podemos considerar que el valor de las causas sociales se incrementa con las aportaciones de las ideas creativas y la estrategia de la publicidad social dirigida al cambio social. Y que ésta, hoy en día, va dirigida al control de las emociones y de los sentimientos. De manera que la publicidad social será más eficiente en tanto en cuanto su creatividad sirva para transformar el odio en amor, trascendiendo a la fatiga de la compasión y difunda los ideales de defensa de la dignidad humana, que se manifiestan en el ámbito de 
la pluralidad a través de la defensa de los derechos humanos y de la defensa del medio ambiente.

Las metáforas que crea la Publicidad Social favorecen la toma de decisiones de sus voluntarios, beneficiarios, donantes, etc. en la medida en que sus promesas facilitan la elaboración de juicios morales que permiten discriminar lo bueno de lo malo.

Por tanto, los fines de la publicidad social difieren de los fines de la publicidad comercial, ya que tiene por objeto favorecer la responsabilidad de las personas en el ámbito de la solidaridad y hacer visibles las contradicciones de la nueva ideología dominante.

Los objetivos de la publicidad social favorecen el desarrollo de la inteligencia social en la medida en que robustecen la pluralidad de ideas para ampliar los indicadores de economía social colectiva. Por tanto, ayudan a definir los indicadores de felicidad con propuesta que facilitan asumir límites a nivel individual.

La comunicación en el ámbito del Marketing de las ideas o Marketing social para el cambio social, ayudada por la creatividad, convierte las promesas en compromisos ineludibles y se aprovecha de las aportaciones de la biopolítica y la neuroética para transformar los valores tradicionales en nuevas representaciones en el imaginario social. La biopolítica transforma los hábitos de comportamiento de la población que forman parte de la vida cotidiana y favorece la formación de los actuales modelos de virtudes públicas. La neuroética corrobora la paradoja del altruismo que contrapone al imperativo neuroético.

Por todo ello, es necesario cultivar y educar las emociones a través de objetivos de sensibilización, difusión y educación a favor de las causas sociales porque solo desde el conocimiento de los problemas y el respeto a los límites que imponen los principios éticos, podremos alcanzar el fin último de la dignidad humana, la felicidad.

\section{REFERENCIAS BIBLIOGRÁFICAS}

AECID (2011): Informe ONGD [En línea consultado el 13/04/2012 en: http://www.aecid.es/galerias/ongds/descargas/INFORME_ONGD_2011.pdf].

Agamben, Giorgio (1998): Homo sacer. El poder soberano y la nüda vida. Valencia: Pre-Textos.

Alvarado, María Cruz; De Andrés, Susana (2005): "Una reflexión crítica sobre la publicidad estatal. El estado ¿anunciante social?" Madrid: Telos. $\mathrm{n}^{\circ}$ 69. [En línea consultado el 23 de septiembre de 2009 en: http://sociedadinformacion.fundacion.telefonica.com/telos/home.asp@idrevistaant $=64 . \mathrm{htm}]$.

Alvarado, María Cruz (2003): La publicidad social: una modalidad emergente de comunicación. Tesis Doctoral de la Universidad Complutense de Madrid.

http://eprints.ucm.es/view/divisions/167.html

ARROYO Isidoro y MARTín, Raquel (2011): "La utilización de Internet en la comunicación expresiva de las ONG: Estudio exploratorio comparativo entre Argentina y España. Bilbao: Zer, 16, nº 31: 243-263. 
Arroyo, Isidoro (2006): "Los valores sociales en la creatividad publicitaria". Madrid: Revista ICONO14, 6, [En línea consultado el 08 de 03 de 2012, de http://www.icono14.net/index.php/revista/historico/ano-3-2005/creatividad].

Arroyo, Isidoro et al (2009): "Publicidad social en las ONG de Córdoba (Argentina). Perfiles de la construcción del mensaje". La Laguna (Tenerife): Revista Latina de Comunicación Social, 64, pp. 1.011 a 1.029. [Consultado el 08 de 03 de 2012 en: http://www.revistalatinacs.org/09/art/877 Fuenlabrada/78 126 Isidoro Arroyo et al.html DOI: 10.4185/RLCS-64-2009-877-1.011-1.029 ].

Arroyo, Isidoro, MAMIC, Lilia Ivana (2009): "Valores Occidentales en el Discurso Publicitario Audiovisual Argentino". Madrid: Revista ICONO14, no 13, pp. 8-23. [En línea consultado el 08 de 03 de 2012, de http://www.icono14.net/index.php/monografico/valores-occidentales-en-el-discurso-publicitario-audiovisual-argentino].

Arroyo, Isidoro; BAÑos, Miguel; RodríGueZ, Teresa (2012): "Modelo de investigación de las piezas audiovisuales de las organizaciones del tercer sector en redes sociales". En Moragas, M.; López, B. \& García, R. Comunicación y Riesgo. Tarragona: Actas del Congreso AE-IC 2012 pp.1-18.

BALAS, Montserrat (2011): La gestión de la comunicación en el Tercer Sector. Madrid: ESIC.

BAÑos, Miguel; Rodríguez, Teresa (2009): "Desarrollo de un Modelo de Predicción de la Eficacia para la Publicidad Social”. Revista ICONO14, n ${ }^{\circ} 13$, pp. 214-238. [consultado el 8/03/2012 de http://www.icono14.net/index.php/monografico/desarrollo-de-un-modelo-de-prediccion-de-la-eficacia-para-la-publicidad-social].

BAÑos, Miguel y RodríGueZ, Teresa (2011): "Las comunicaciones de las ONG en medios virtuales 3D. Un estudio exploratorio en Second Life". Madrid: Comunicación y Hombre, $\mathrm{N}^{\mathrm{o}}$ 7, pp.61-83.

BERLIN, Isaiah (1958): "Two Concepts of Liberty". [consultado el 08/03/2012 en: http://www1.nsd131.org/classpages/bwilliamson/Shared\%20Documents/Two\%20C oncepts $\% 20$ of $\% 20$ Liberty $\% 20$ Berlin.pdf].

BeltrÁn, Luis Ramiro (2007): “Adiós a Aristóteles: La comunicación horizontal”. Sao Paulo (Brasil): Revista Latinoamericana de Ciencias de la Comunicación, año IV, $\mathrm{n}^{\mathrm{o}}$ 7, pp.12-36.

BELTRÁN, Luis Ramiro (2008): "Comunicación: herramienta olvidada del desarrollo nacional". En GuMUcio, A. y TuFTE T. (coord): Antología de comunicación para el cambio social, lecturas históricas y contemporáneas, La Paz (Bolivia): Plural Editores, pp. 36

Betsey, Stevenson, WolfERs, Justin (2008): "Economic Growth and Subjective Well Being: Reassessing the Easterlin Paradox". Baltimore (U.S.A.): Brookings Papers on Economic Activity (Spring), pp.1 87.

Boltanski, Luc; Chiapello, Eva (2002) El nuevo espíritu del capitalismo. Madrid: Akal.

Caravantes, Marta (2011): “Comunicar con creatividad” en Martínez-Gómez, Raquel y Lubetkin, Mario (coord.): Políticas, Redes y Tecnologías en la Comunicación, Sevilla-Zamora: Comunicación Social. pp. 155-166.

Corral, Margarita (2011): "La economía de la felicidad" en Perspectivas desde el Barómetro de las Américas, Número 58. Nashville: Vanderbilt University, pp.1-10.

CortinA, Adela (2011): Neuroética y Neuropolítica. Madrid: Tecnos. 
Damasio, Antonio (2005): En busca de Spinoza. Neurobiología de la emoción y los sentimientos. Barcelona: Critica

De Andrés DEl CAMPO, Susana (2010): “Tercer tiempo para la publicidad. De las funciones a los fines de un metafenónemo”. DE ANDRÉS DEL CAMPO,, Susana (coord..) Otros fines de la publicidad, Sevilla- Zamora: Comunicación Social, pp. 47-74.

Del Río, Olga (2011): "TIC para el Desarrollo Humano y participación de la Sociedad Civil”. en Martínez-Gómez, Raquel y Lubetkin, Mario (coord.): Políticas, Redes y Tecnologías en la Comunicación, Sevilla-Zamora: Comunicación Social, pp. 37-46

Di Tella, Rafael, Dubra, Juan, Macculloch. Robert (2008): "Gross National Happiness as an Answer to the Easterlin Paradox?" Elsevier: Journal of Development Economics, no 86, pp.22- 42.

EASTERLIN, Richard (1995): "Will Raising the Incomes of All Increase the Happiness of All?" Elservier: Journal of Economic Behavior and Organization, n 27, pp.35-47.

ERRO, Javier (2003): Descubrir y construir procesos de comunicación social. Bilbao: Hegoa [consultado 13/04/2012 http://publ.hegoa.efaber.net/publications/185].

EsPosito, Roberto (2004): Bios: biopolitica e filosofia. Torino: Einaudi.

FORD, Liz (2011): "El proyecto Katine: un nuevo enfoque en la comunicación sobre el desarrollo" en MArTínez-Gómez, Raquel y LubetKIn, Mario (coord.): Políticas, Redes y Tecnologías en la Comunicación, Sevilla-Zamora: Comunicación Social, pp.167-176.

FouCAUlt, Michel (2009): Nacimiento de la biopolítica. Madrid: Akal.

FuKuJAma, Francis (1992): El fin de la historia y el último hombre. Barcelona: Planeta. GómEZ, Carlos (2004): Las ONG en la sociedad global. Estrategias de las ONG frente al Estado en la era de la globalización. Bilbao: Cuadernos Bakeaz, 65, pp 1-15.

Graham, Carol; PetTinat, Stefano (2001): "Happiness, Markets and Democracy: Latin America in Comparative Perspective." Springer: Journal of Happiness Studies (2), pp. 237-268.

HeRRANZ DE LA CASA, José María (2007): “La gestión de la comunicación como elemento generador de transparencia en las organizaciones no lucrativas" CIRIEC, 57, pp. 5-31. [consultado el 08/03/2012 de http://www.ciriecrevistaeconomia.es/banco/5701 Herranz.pdf].

Himmelfarb, Gertrude (1995): The de-moralization of society: From Victorian virtues to modern value. New York: A.A. Knopf.

KaPlún, Mario (1998): Una Pedagogía de la Comunicación. Madrid: Ediciones de la Torre.

KotLer, Philip; RoBerto, Eduardo (1992): Marketing social. Estrategias para cambiar la conducta pública. Madrid: Editorial Díaz Santos.

LATORRE, Xavier (2001): "El marketing aplicado a las ONGD: coherencias e incoherencias en relación con la educación para el desarrollo". Huelva: Comunicar, 16, pp.103114.

LIPOVETSKY, Gilles (2011): "El reino de la hipercultura: cosmopolitismo y civilización occidental" en LiPOVETSKY, Gilles y JuVIN, Hervé: El occidente globalizado, Barcelona: Anagrama, pp. 11-102.

MARÍ, Víctor (2007): "Contra la evaporación de la dimensión política de la comunicación. Movimientos sociales, ONG y usos de Internet”. En Bilbao: Zer, nº 22, pp. 453 471. 
Marina, José Antonio (2011): Pequeño tratado de los grandes vicios. Barcelona: Anagrama.

Martín Requero, María Isabel (2010): “Comunicación y altruismo. Construir confianza para combatir la crisis" en De Andrés del Campo, Susana (coord..) Otros fines de la publicidad, Sevilla- Zamora: Comunicación Social, pp.13-46.

MarTín, Raquel (2010): La comunicación web del Tercer Sector: Análisis estructural de los sitios web de las ONGD calificadas por la Agencia Española de Cooperación Internacional para el Desarrollo. Tesis doctoral, Universidad Rey Juan Carlos: Madrid.

Mendiz, Alfonso; Victoria, Juan Salvador, Arroyo, Isidoro (2013). La eficacia de la publicidad social en las redes sociales. Un experimento online con usuarios jóvenes. Razón y Palabra, 82, pp. 1-19. [consultado el 01/04/2013 de http://www.razonypalabra.org.mx/N/N82/V82/25_MendizVictoriaArroyo_V82.pdf].

Nos AlDAS, Eloisa (2010): “Comunicación, cultura y educación para la solidaridad y el desarrollo. Un análisis desde el discurso". En: Burgui T. y ERro J. (Coord.) Comunicando para la solidaridad y la cooperación. Cómo salir de la encrucijada, pp. 113-135. Pamplona: Foro Comunicación, Educación y Ciudadanía.

PACHECO, Marta (2010): "La contrapublicidad verde como metadiscurso de denuncia" en De Andrés DEl CAMPo, Susana (coord..) Otros fines de la publicidad, pp.108-135. Sevilla- Zamora: Comunicación Social.

RAu DE AlmeidA, Manuela (2006):“Comunicación, participación y ciudadanía: elementos de la comunicación para el desarrollo en el Proyecto Jóvenes Comunicadores Pernambuco -Brasil’". São Leopoldo - RS - (Brasil): UNIrevista. Julio 2006, vol. 1, $n^{\circ} 3$.

SAIZ, Vanessa (2008): "Resolución de la distancia moral a través de la mediación experta de las ONGD”. Madrid: CIC Cuadernos de Información y Comunicación, vol. 13, pp. 79-106.

SEARLE, John Rogers (2000): Razones para actuar. Una teoría del libre albedrío. Oviedo: Ediciones Nobel.

SERrAno, Vicente (2011): La herida de Spinoza. Felicidad y política en la vida posmoderna. Barcelona: Anagrama.

Unger, Peter (1996): Living high and letting die: Our illusion of innocence. New York: Oxford University Press.

Zorn, Theodore E., Flanagin, Andrew J. y Shoham, Mirit (2011): "Institutional and noninstitutional influences on information and communication technology adoption and use among nonprofit organizations". Wiley: Human Communication Research, no 37, pp. 1-33. 


\title{
RESUMEN
}

El espacio de las ideas de la comunicación social está ocupado por un amplio y plural tejido asociativo. Todas esas ideologías comparten el denominador común de la cultura moderna, el pluralismo. Estamos ante un nuevo sistema de creencias que impone un sentimiento básico que domina la visión del mundo, el de la voluntad de poder. Esta nueva ideología triunfante se las tiene que ver con sus propias contradicciones para organizar y jerarquizar los afectos y favorecer las aspiraciones de justicia, de ética y de pluralismo y para favorecer la inteligencia social que resuelva el problema de transformar la necesidad de bienestar de la sociedad en una necesidad individual a satisfacer. La publicidad social ayuda a resolver esa contradicción y utiliza las aportaciones de la creatividad, la biopolítica y la neuroética.

Palabras clave: Cambio social, ONG, ideas, publicidad social, biopolítica y neuroética.

\begin{abstract}
The space of social communication ideas is occupied by a large and diverse network of associations. All these ideologies share the common denominator of modern culture, pluralism. We are facing a new belief system that imposes basic feeling that dominates the world view, the will to power. The triumphant new ideology involves their own contradictions and it must organize and prioritize the desire for justice, ethics and pluralism. It must encourage social intelligence to solve the problem of transforming the welfare needs of society into an individual need. Social advertising helps resolve this contradiction and uses the contributions of creativity, biopolitics, and neuroethics.
\end{abstract}

Keywords: Social change, nonprofit, ideas, social advertising, biopolitics, neuroethics.

\section{RÉSUMÉ}

L'espace des idées de la communication sociale est occupé par un tissu associatif large et pluriel. Toutes ces idéologies partagent le dénominateur commun de la culture moderne, pluraliste. Nous avons un nouveau système de croyance qui impose un sens élémentaire qui domine la vision du monde, de la volonté de puissance. Cette nouvelle idéologie triomphante a leurs propres contradictions, et elle doît organiser et classer l'affection et promouvoir les aspirations de la Justice, l'éthique et le pluralisme et favoriser l'intelligence sociale afin de résoudre le problème de la transformation du bien-être de la société que doît devenir le besoin de bien-être en un besoin individuel pour répondre. La publicité sociale permet de résoudre cette contradiction et utilise les contributions de la biopolitique, la créativité et la neuroéthique.

Mots clé: Changement social, non-profit, idées, publicité sociale, biopolitique, neuroéthique. 